\title{
PENGEMBANGAN APLIKASI PERMAINAN SCRABBLE DUA BAHASA MENGGUNAKAN JAVA
}

\author{
Fajar Masya; Elvina
}

\author{
Jurusan Teknik Informatika, Universitas Mercu Buana Jakarta \\ fmasya67@gmail.com, elvina.fajar@yahoo.com
}

\begin{abstract}
Game applications are favored by many computer users. The population of Indonesia, especially common people do not like playing games in a foreign language. Yet such games can be a fun learning media for foreign languages, especially English. Hence, we developed a game application using the concept of the game Scrabble. The design of this application uses a waterfall methodology, with application design modeling with UML diagrams (Unified Modelling Language) including Use Case Diagram, Activity Diagram, Statechart Diagram, Class Diagram and Sequence Diagram. In the implementation phase, Blue J software used to build the interface using the Java Development Kit (JDK) version jdk1.6.0 02 as the executor, as well as using the command prompt to call the results of execution. Tests on gaming applications are performed using the Black Box and White Box method. The product of this development is a single player game application, which uses two language options.
\end{abstract}

Keywords: game applications, Scrabble, waterfall software engineering methodologies, UML (Unified Modeling Language), Java Programming.

\begin{abstract}
ABSTRAK
Aplikasi game merupakan salah satu jenis aplikasi yang sangat digemari oleh banyak pengguna komputer. Namun sangat disayangkan jarang ditemukan permainan bertaraf internasional banyak digemari oleh banyak Penduduk Indonesia khususnya masyarakat awam yang kurang menyukai permainan dalam bahasa asing. Selain itu, permainan itu juga bisa dijadikan media pembelajaran yang menyenangkan bagi semua usia, terhadap bahasa asing pada umumnya Bahasa Inggris terutama anak-anak jenjang SD sampai SMA atau sederajat. Oleh karena itulah penulis mengembangkan sebuah aplikasi game dengan menggunakan konsep permainan Scrabble. Dalam perancanganya penulis menggunakan metodologi rekayasa perangkat lunak waterfall, yaitu dengan pemodelan perancangan aplikasi pada diagram UML (Unified Modelling Language) diantaranya Use Case Diagram, Activity Diagram, Statechart Diagram, Class Diagram dan Sequence Diagram. Pada tahap implementasi penulis menggunakan perangkat lunak Blue J untuk membangun antarmuka dengan menggunakan Java Development Kit (JDK) versi jdk1.6.0_02 sebagai perangkat pengeksekusi, serta menggunakan command prompt untuk pemanggilan hasil eksekusi. Sedangkan pengujian terhadap aplikasi game dilakukan dengan metode Black Box dan White Box. Produk dari pengembangan tersebut adalah sebuah aplikasi game single player, yang menggunakan dua pilihan bahasa dalam permainannya, dan dinamakan "Scrabble Dua Bahasa".
\end{abstract}

Kata kunci: Aplikasi game, Scrabble, metodologi rekayasa perangkat lunak waterfall, UML (Unified Modelling Language), Pemrograman Java.

\section{PENDAHULUAN}

Dewasa ini banyak permainan yang diperkenalkan ke masyarakat umum, namun tidak semuanya memiliki dampak positif dalam kehidupan, terutama bagi anak-anak usia SDSMA yang bisa sangat mengganggu dalam hal pendidikan. Scrabble menjadi pilihan permainan yang cenderung memiliki dampak positif untuk permasalahan tersebut (Whisenand \& Dunphy, 2010; Quinn \& Wiest, 1999). Scrabble adalah suatu permainan menyusun huruf-huruf menjadi sebuah kata. Selain dapat dijadikan sebagai media pembelajaran yang menarik, permainan scrabble dua bahasa ini dibuat sebagai salah satu cara untuk menambah daya tarik permainan scrabble dikalangan masyarakat indonesia. Permainan ini sudah populer dikalangan masyarakat dunia, sehingga negaranegara bagian di dunia telah mengembangkan permainan scrabble ke dalam bahasa negara mereka dari Bahasa Inggris sebagai Bahasa Induk dari permainan scrabble tersebut. Dari uraian tersebut dapat ditarik suatu rumusan masalah yaitu bagaimana mengembangkan permainan scrabble yang memiliki kamus permainan dalam Bahasa Indonesia dan mengimplementasikannya kedalam suatu aplikasi untuk personal komputer (PC). Dalam implementasi perancangan game ini mempunyai batasan masalah sebagai berikut: (1) Pembuatan aplikasi scrabble dengan pilihan dua kamus bahasa yaitu Bahasa Indonesia dan Bahasa Inggris,tetapi hanya memiliki Bahasa Inggris sebagai latar belakang bahasa petunjuk dalam permainan; (2) Ukuran atau jumlah kotak pada papan tempat menyusun huruf (papan scrabble) adalah $15 \times 15$ (baris x kolom) dan untuk persediaan huruf (letter) adalah 7 buah kotak huruf; (3) Tingkat Kesulitan dibagi tiga, yaitu: mudah, sedang, dan sulit; dan (4) Aplikasi permainan yang akan dibangun hanya dapat dimainkan oleh satu orang pemain.

\section{METODE PENELITIAN}

Dalam penyusunan laporan tugas akhir ini, metode rekayasa perangkat lunak yang digunakan adalah metode Waterfall. Metode Waterfall mengusulkan sebuah pendekatan kepada perkembangan perangkat lunak yang sistematik dan sekuensial yang mulai pada tingkat dan kemajuan sistem pada 
seluruh analisis, desain, kode, pengujian, dan pemeliharaan. Metode ini terdiri dari beberapa tahapan, yaitu: tahap analisis, perancangan (design), pengkodean, dan pengujian. Tahapantahapan dalam metode Waterfall dapat dilihat pada berikut:

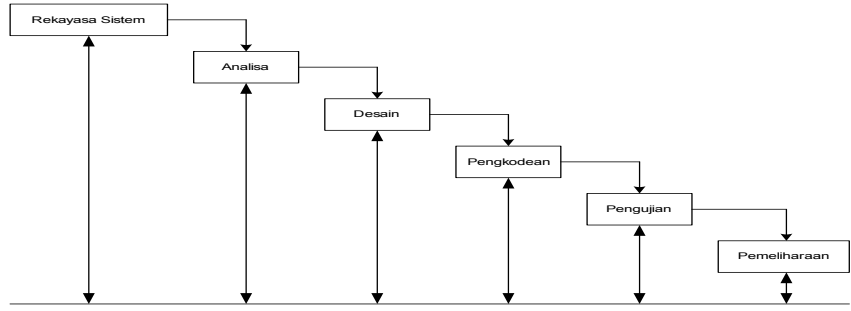

Gambar 1. Model Waterfall (Pohan \& Bahri, 1997)

\section{Perancangan Sistem}

Pada tahap perancangan sistem aplikasi permainan scrabble dua bahasa ini menggunakan Unified Modeling Language (UML) adalah sebuah "bahasa" yang telah menjadi standar dalam industri untuk visualisasi, merancang dan mendokumentasikan sistem piranti lunak. UML menawarkan sebuah standar untuk merancang model sebuah sistem.

Berikut ini akan dijelaskan diagram dasar dalam UML yaitu: Use Case Diagram, Aktivity Diagram, Sequnce Diagram, Statechart Diagram, dan Class Diagram.
1.Use Case Diagram Aplikasi

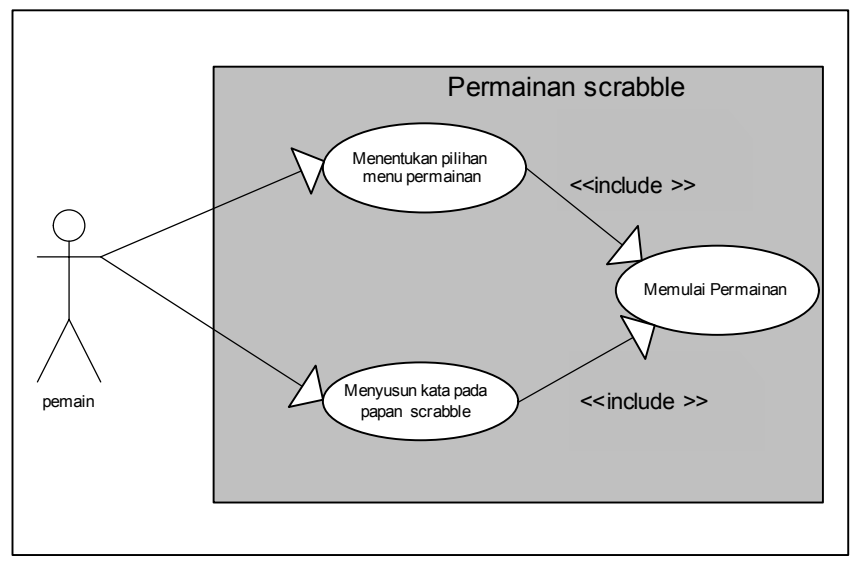

Gambar2.UseCase Diagram Memulai Permainan

2. Aktivity Diagram (Diagram ktifitas)

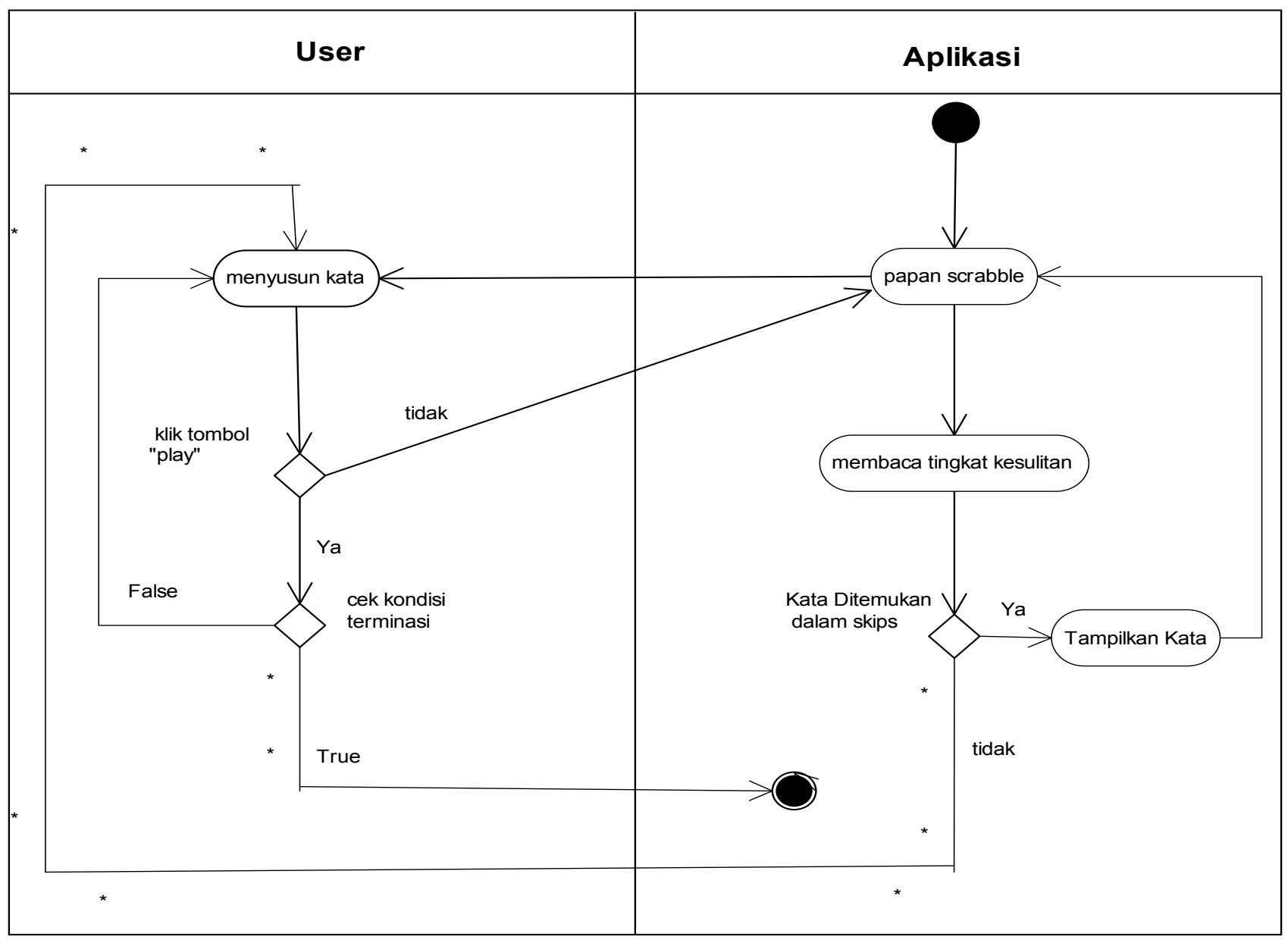

Gambar 3. Diagram aktifitas untuk use case menyusun kata 


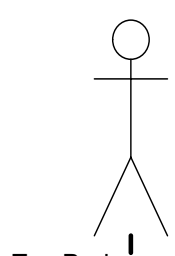

Top Package:::pemain

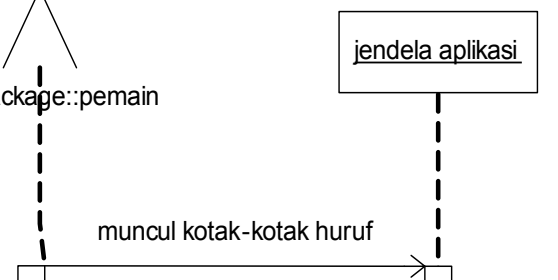

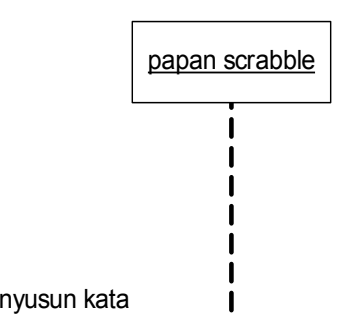

kata ada dalam kamus

Klik 'Restore'
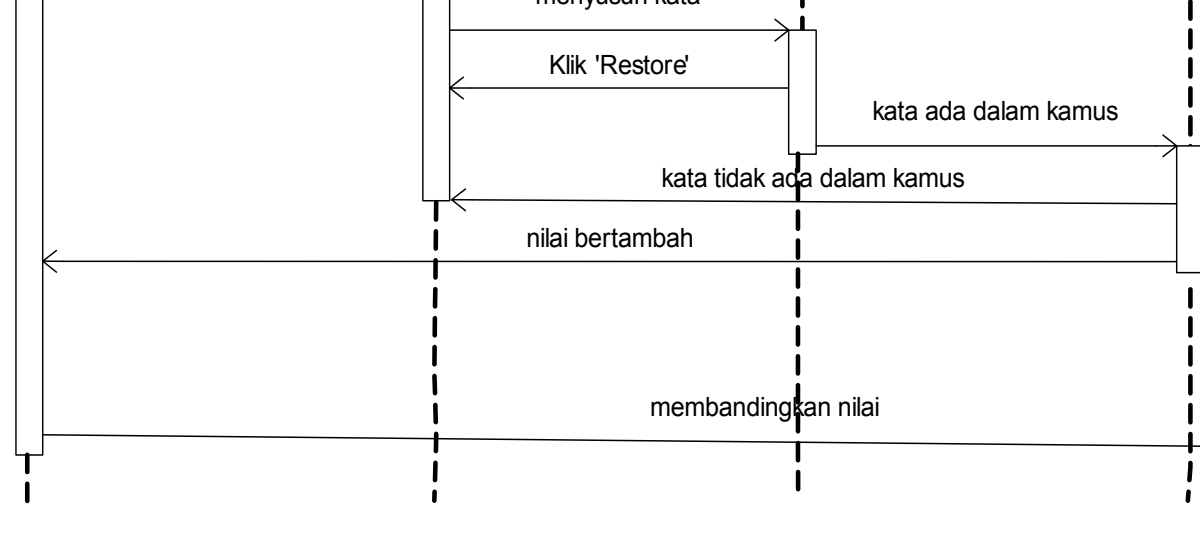

Gambar 4. Sequence Diagram menyusun kata

\section{Statechart Diagram}

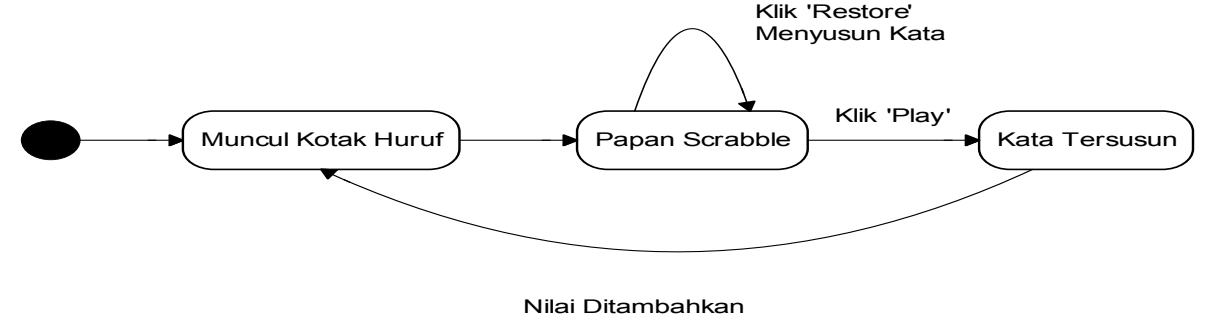

Gambar 5. Statechart Diagram menyusun kata

\section{Class Diagram}

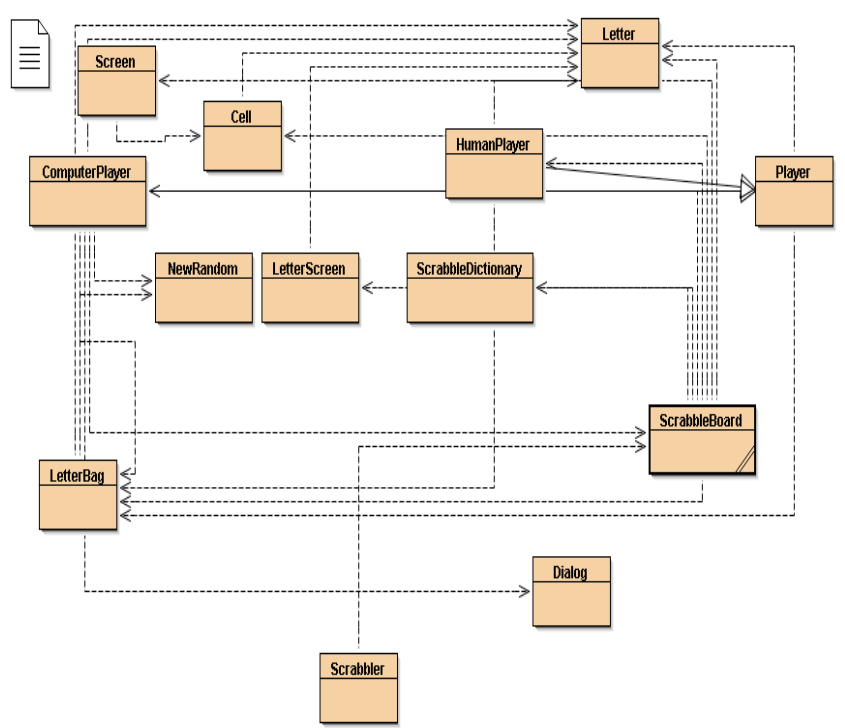

Gambar 6. Class Diagram Permainan Scrabble Dua 


\section{PENGUJIAN}

\section{HASIL DAN PEMBAHASAN}

\section{Kompilasi Program Java}

Berikut ini adalah langkah-langkah eksekusi program java melalui command promp:

1. Buka perintah command prompt (cmd ) pada start di windows.

2. Ketikkan perintah cmd pada kotak perintah.

3. Tuliskan direktori yang menyimpan file aplikasi yang akan di eksekusi, misalkan ( d: ) lalu tekan "enter" pada keyboard.

4. Jika direktori yang dituju belum ditemukan, pindahkan pilihan pada direktori yang lain dengan fungsi change directory (cd) lalu direktori tujuan.

5. Merubah semua file. Java menjadi file. Class dengan menggunakan kata kunci javac. Scrabbler. Java.

6. Eksekusi kembali dengan menggunakan kata kunci java. Scrabbler, dan jendela aplikasi pilihan menu akan muncul.

7. Aplikasi permainan telah berhasil di eksekusi dan siap untuk digunakan. Secara singkatnya dapat dilihat pada gambar 4.18 sebagai berikut :

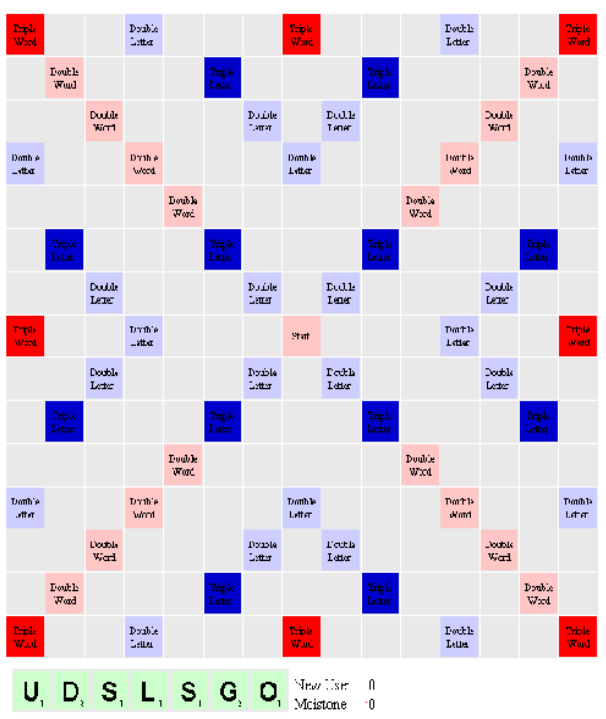

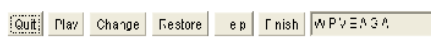

Gambar 9. Tampilan Jendela Permainan Utama

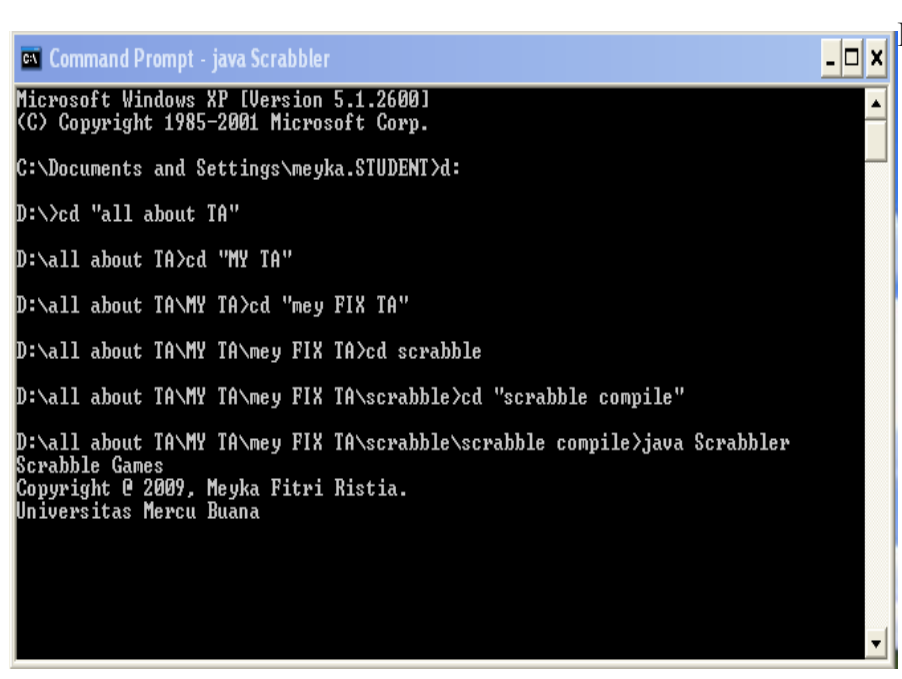

Gambar 7. Langkah-langkah Eksekusi Melalui Command Prompt ( cmd)

\section{Hasil Pengujian Program}

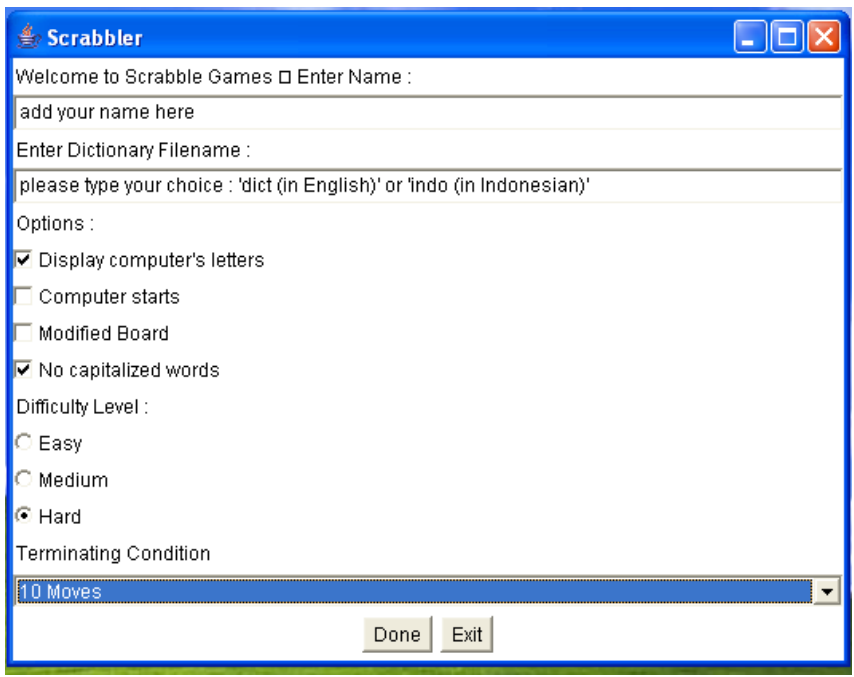

Gambar 8. Tampilan Jendela Menu Utama

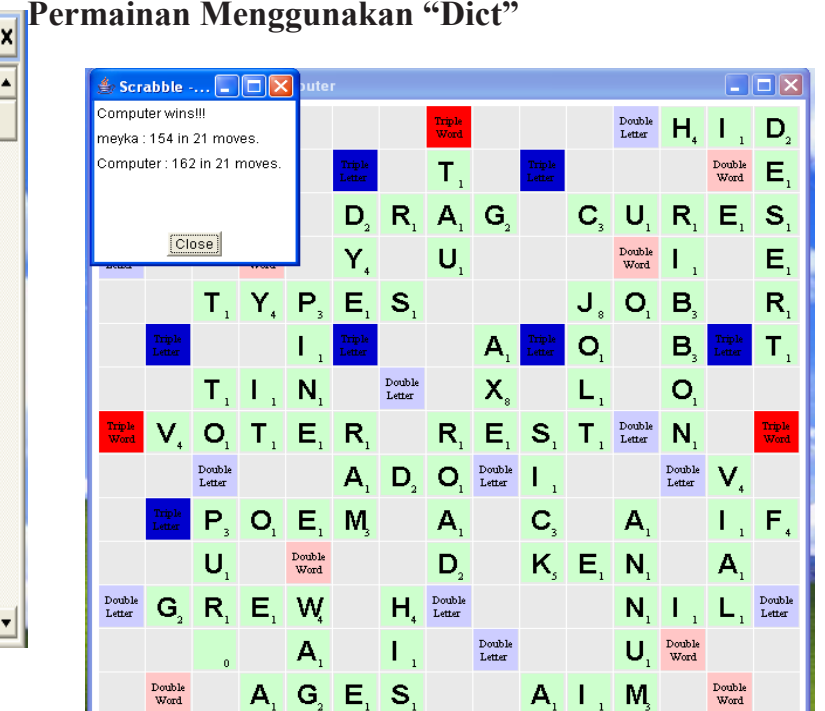

Gambar 10. Tampilan Permainan "dict" dengan tingkat kesulitan easy

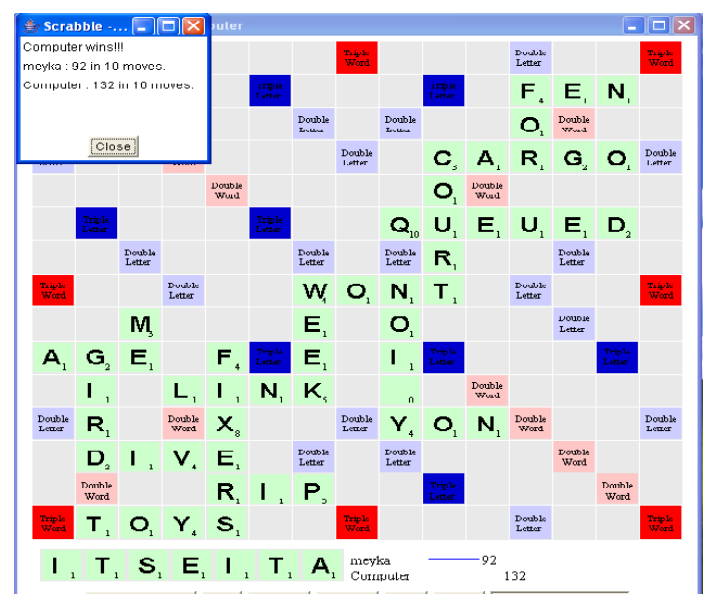

Gambar 11.Tampilan Permainan "dict" dengan tingkat kesulitan medium 


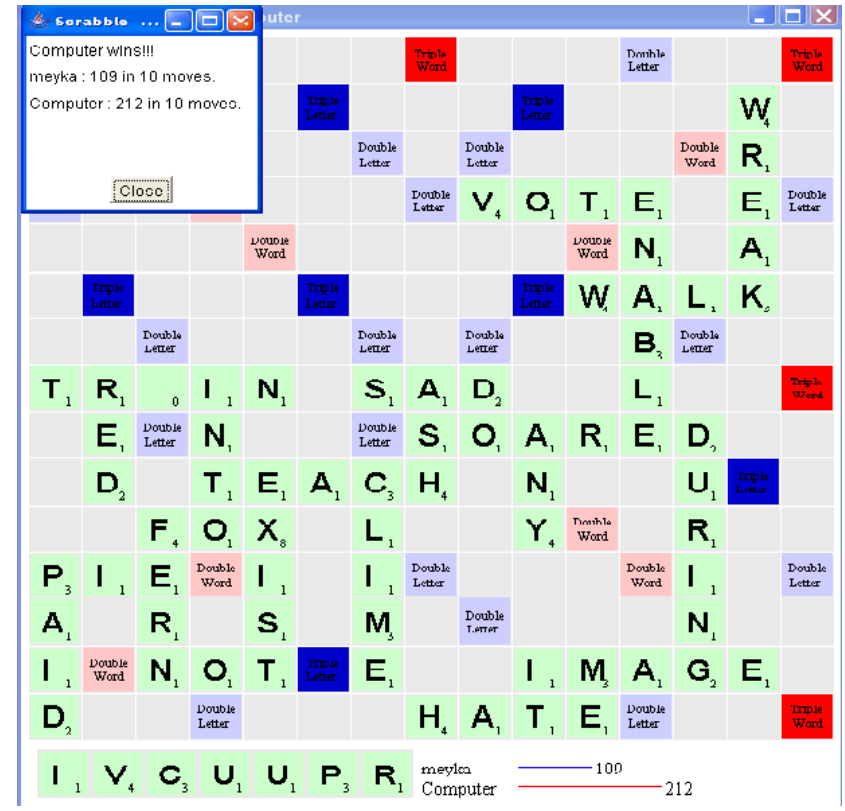

Gambar 12.Tampilan Permainan "dict" dengan tingkat kesulitan hard

Dari gambar 10-12, perbedaan terletak pada tingkat kesulitan yang diukur dari nilai point computer player dari kata yang ditampilkan. Dari gambar 10, permainan dengan pilihan easy dan dalam 21 moves, komputer player dapat mengumpulkan nilai sebanyak 162 poin. Dari gambar 11, dengan tingkat kesulitan medium dalam 10 moves, komputer player mengumpulkan 132 poin. Dari gambar 12, dengan tingkat kesulitan hard dalam 10 moves,nilai yang dikumpulkan 212 poin

\section{Permainan Menggunakan "indo"}

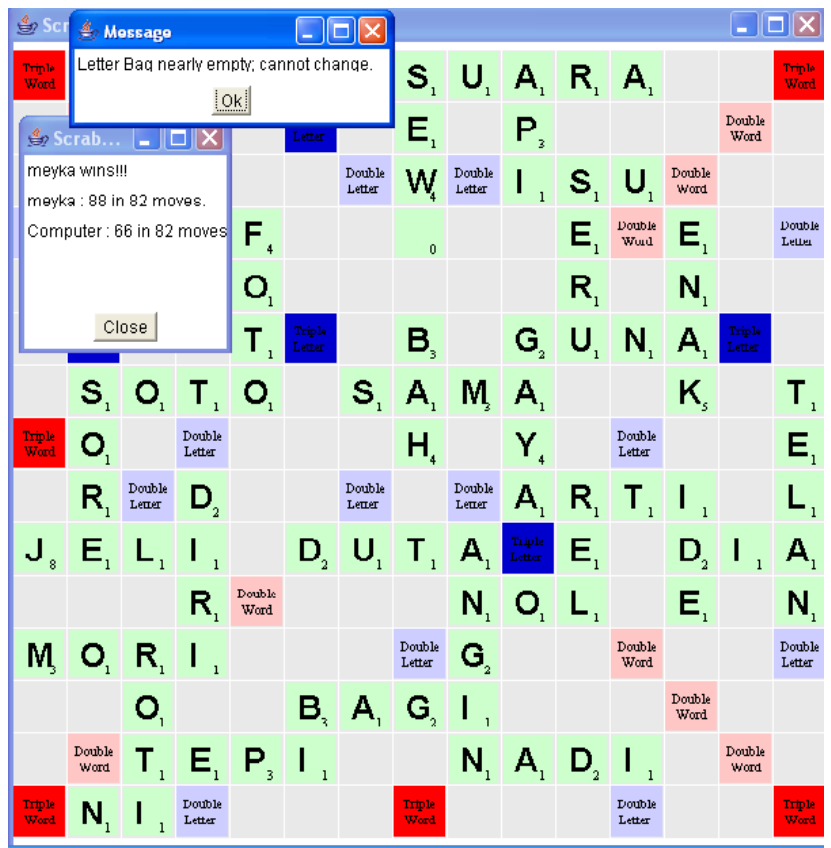

Gambar 13.Tampilan Permainan "indo" dengan tingkat kesulitan easy
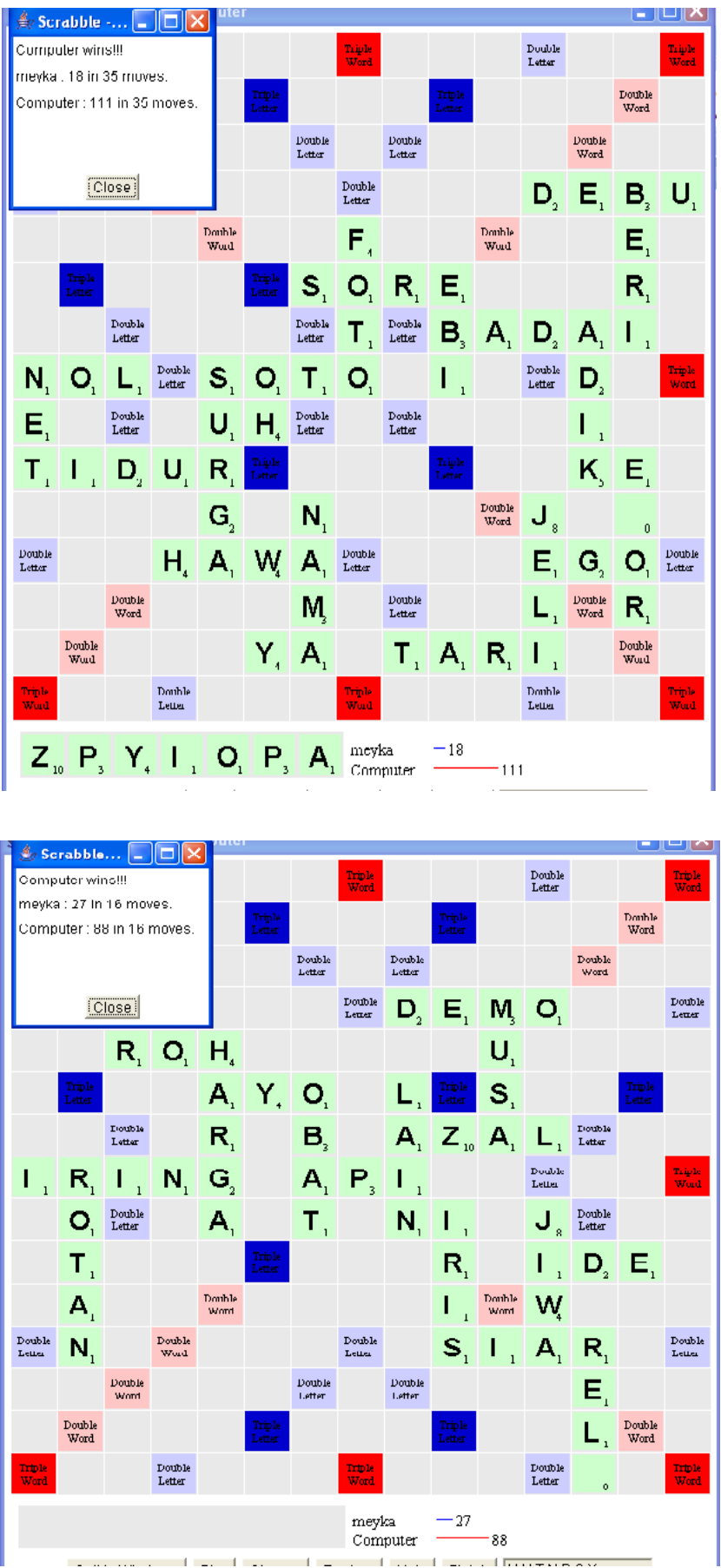

Gambar 14.Tampilan Permainan "indo" dengan tingkat kesulitan medium

Dari percobaan menggunakan indo, untuk setiap tingkatan kesulitan memiliki hasil yang sama untuk permainan dengan menggunakan dict. Dari gambar 13 - 15, dapat dilihat permainan dengan tingkat kesulitan yang berbeda. Pada gambar 13, dengan tingkat kesulitan easy, komputer dapat mengumpulkan nilai sebanyak 66 poin dalam 88 moves. Pada gambar 14, dengan tingkat kesulitan medium, komputer mengumpulkan nilai sebanyak 111 poin dalam 33 moves. Sedangkan pada gambar 15, dengan tingkat kesulitan hard, komputer dapat mengumpulkan nilai sebanyak 88 poin hanya dalam kondisi 16 moves. berikut:

Perbedaan tersebut dapat dilihat dalam diagram alir 


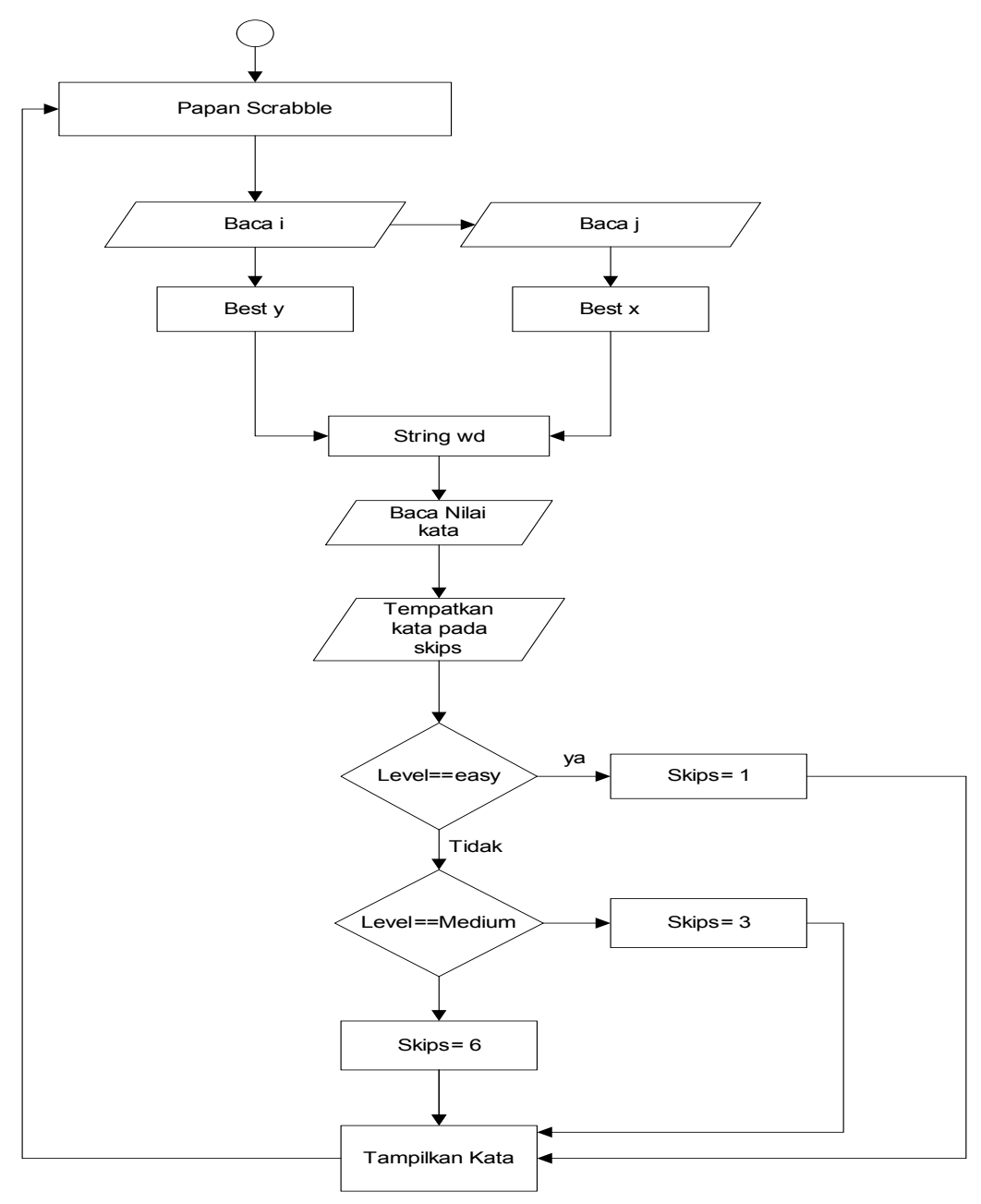

Gambar 15.Diagram Alir tingkat kesulitan

Tingkat kesulitan tersebut diukur dari varibel skips yaitu tingkatan dalam penempatan kemungkinan kata yang terbentuk pada saat computer membaca huruf-huruf dari papan scrabble yaitu matriks $\mathrm{i}$ (sumbu vertikal) dan $\mathrm{j}$ (sumbu horizontal) maupun kotak huruf (letter). Setiap kata yang terbentuk disimpan ke dalam variable string wd terlebih dahulu sebelum ditempatkan pada susunan skips. Penempatan susunan pada skips ditentukan berdasarkan nilai total dari poin huruf yang membentuknya. Skips memiliki 6 tingkatan, dimana tingkatan dimulai dari nilai terkecil (1) sampai nilai terbesar (6). Untuk pilihan easy kata-kata yang akan ditampilkan ke dalam papan scrabble adalah kata pada urutan skips ke-1, sedangkan untuk medium yang akan ditampilkan adalah kata pada urutan skips ke-3, dan pada skips ke-6 untuk pilihan hard.

\section{SIMPULAN}

Dengan menggunakan metode rekayasa perangkat lunak waterfall, pada tahap analisis masalah maka diperoleh model permasalahan pada Aplikasi Permainan Scrabble dua bahasa ini, yaitu bagaimana suatu program java dapat mengidentifikasi string untuk pembacaan nama file kamus yang diinput dari user.Pada tahap perancangan aplikasi dirumuskan sifat atau rancangan dari sistem ini, yang kemudian telah diimplementasikan hingga menjadi sebuah program yang utuh. Lalu pengujian unit dan integrasi menunjukan bahwa Aplikasi Permainan Scrabble dua bahasa ini secara fungsional bekerja dengan baik sesuai kebutuhan yang telah didefinisikan pada tahap analisis sampai perancangan. Metode pengujian yang digunakan adalah metode black box dan white box. Aplikasi Permainan Scrabble dua bahasa telah dapat dimainkan selayaknya permainan scrabble biasa. Dengan adanya penerapan bahasa Indonesia sebagai kosakata dalam kamus aplikasi, Sehingga diharapkan aplikasi ini turut mempopulerkan Bahasa Indonesia dalam permainan internasional ini, khususnya bagi Warga Indonesia sendiri.

\section{DAFTAR PUSTAKA}

Pohan, H. I., \& Bahri, K. S. (1997). Pengantar Perancangan Sistem. Jakarta: Erlangga, 1997.

Quinn, R. J., \& Wiest, L. R. (1999). Reinventing scrabble with middle school students, Mathematics Teaching in the Middle School. Reston: Dec 1999. Vol. 5, Iss. 4; pg. 210

Whisenand, T. G., \& Dunphy, S. M. (2010). Accelerating Student Learning of Technology Terms: The Crossword Puzzle Exercise, Journal of Information Systems Education. West Lafayette: Summer 2010. Vol. 21, Iss. 2; pg. 141, 8 pgs 